\title{
The Effect of a Changing Environment on the Requirements for Engine Materials
}

\author{
J. C. Williams \\ GE Aircraft Engines \\ Cincinnati, OH 45215-6301
}

\begin{abstract}
This paper attempts to examine the changes in the external environment which the aircraft engine industry is facing. Among the changes is the transition from a strong dependence on military programs to a commercially driven business. This changing environment has a significant effect on business plans, the way that business decisions are made, and the manner in which business is conducted. These factors directly affect the time horizons and nature of new materials technology implementation. Also affected is the funding available for materials and process development. As the focus of the propulsion industry changes from a predominantly military to a commercial one, a commensurate cultural change must also occur. In particular, speed to market and shortening of the product cycle will become more important. This will be a challenge in the engine business which has a long product cycle. One approach to this is recognized to be adoption of integrated product development (IPD). Some of the dimensions of the business climate changes and the potential for a reduction of the product development cycle are discussed in the context of their impact on materials technology.
\end{abstract}




\section{Introduction}

It is, perhaps, instructive to ponder the changes in the world which have occurred in the four years that have passed since the last Seven Springs Conference on Superalloys. For example, the Iron Curtain has come down, Germany has re-unified, the Soviet Union is now the Former Soviet Union, there has been a major conflict in the Persian Gulf, there is an ongoing world-wide recession, the U. S. military budget is undergoing deep cuts, and the engine business is suddenly faced with a significant over capacity situation. Some, if not all, of these discrete changes are inter-related, but that is not the point of this article. The point is that these changes, taken together, dictate sweeping changes in the emphasis and directions of materials development and implementation activities in the propulsion industry. It also means that, unless the current Administration and the Congress wake up to the true implications of the "peace dividend", the aerospace industrial sector will be placed at risk. This would be unfortunate because this sector has been a consistent leader in U. S. exports ( $\$ 29 B$ in 1990). It is clear to the author that the benefits of military spending on the competitiveness of the U. S. propulsion industry have been significant and that the current military budget situation will not allow continued realization of this benefit. Reduced military spending makes sense from an overall national viewpoint. However, the benefits of military spending for specific industrial sectors must be recognized, and steps need to be taken to assure a smooth transition to a commercial economy. At present this is not occurring, and the vital partnership between industry and government which has placed GE and Pratt \& Whitney in world leadership roles in commercial aviation is rapidly being sidetracked by partisan bickering and unrealistic ideology concerning such subjects as Industrial Policy, Export Controls, and Antitrust. Meanwhile, our overseas competitors continue to reduce our competitive lead, in part because they are not being subjected to the same counterproductive pressures from their respective governments.

The technology base of the U. S. aircraft engine industry is in a state of transition. Historically it has been aligned primarily with military requirements, with a spin-off of technology to commercial products. This industry is in rapid transition to a commercial business which has many capabilities which can support the needs of the Defense Department and our national security. Such a transition requires a carefully thought out plan. It is clear that this transition will require an adjustment of priorities, including more rigorous cost-benefit analysis of the value of new materials and process technology, especially those that are high risk and high pay-off. Done carefully, this analysis will produce more focus and discipline in the technology investment planning process. Done poorly and/or expediently, these analyses will jeopardize the long term competitiveness of the industry by opting only for short term initiatives. Meanwhile, our overseas competitors are addressing both present and future needs with the benefit of help from their respective governments. Stated differently, the old paradigm which implied that "hotter and lighter are always better" needs to be replaced by one which asks: "hotter or lighter at what cost and at what pay-off?". Simultaneously, a new metric needs to be added concerning the subject of speed to market or the time required to develop a product. Both of these will require a new mind set and will take time to implement. The time to address these needs is now.

The remaining portions of this paper will examine what is happening in the propulsion industry to effect this transition to a new paradigm and what is being done to remain competitive during the remainder of this decade while positioning ourselves to continue to be competitive in the next century. It is important to emphasize that the ensuing comments are the opinions of the author and in no way 
reflect a company position on these matters. It is hoped, however, that the following discussion bears some relationship to the cultural transformation which is occurring in the propulsion industry. Qualitatively, most of the points made below agree with remarks and writings of many key people in the propulsion industry.

\section{The Business Climate and Its Impact on Materials Technology}

A premise of this section is that the propulsion industry is in a state of transition from a military focussed enterprise to one which is heavily commercial, if not commercially focussed. There is a fundamental difference in financing the development of military and commercial products. In the case of a military product, there are progress payments, i. e. development costs are recovered as the project proceeds (according to the terms of the contract). In the case of a commercial product, all the development costs are invested up front by the development team and subsequently recovered through sales of the product. While this observation is hardly rocket science, it is useful to state clearly here. Surprisingly, this point is not carried in the foreground of the consciousness of many engineers of defense industry companies. The implications of this simple observation are profound. Development costs should only be incurred in commercial product development efforts for things which will pay for themselves through greater customer value. The key term in this statement is "customer value". Definition of this term becomes the center piece by which a new product is judged. In reality, customer value is a complex, multi-faceted concept which ultimately is determined by the customer. Thus, listening carefully to the customer becomes an essential ingredient of success. One commercial product has many customers, some with stronger voices than others. Thus the listening process is complicated and requires skill and experience. Materials people seldom are involved in this process, but the outcome of it has substantial influence on their efforts.

In principle, focus on customer value is equally important for military products, but factors affecting the determination of value are different. For example, there typically is only one military customer for a given product. Additionally, the funding patterns are as often dictated by the vagaries of the Congressional appropriation process as by the needs of the project. Also, the product mission may change during the course of the development program. This tends to reduce the sharpness of mission focus and makes development of ancillary technologies necessary to cover such contingencies. These are among the reasons why a government customer agrees to pay as the development program proceeds. Since the focus of this article is on the changes in environment, the bulk of the remaining discussion will focus on the growing influence of the commercial component of the engine business on the requirements for new materials and processes. However, to leave the reader with the impression that customer value is not important for military engines would be incorrect and totally inappropriate.

To complete this section on the business climate, it is necessary to briefly summarize the materials and process development efforts which have been in progress for the past several years. It also is appropriate to comment on which of these efforts are most affected by the changing climate. This also brings the time frame of this article into some rough registry with the proceedings of the 1988 conference.

In 1988 there was a significant ongoing effort (initiated in 1983) directed toward developing advanced materials for very high thrust to weight demonstrators. This effort was and is known as the IHPTET (Integrated High Performance Turbine Engine Technology) Program. This program was conceived as a "quantum step" program, in 
part as a rubric to re-energize interest in funding aircraft propulsion research. Programs such as this were also part of the contemporary national security strategy to use advanced technology to avoid any "surprises". "Star Wars" was initiated for similar reasons. IHPTET served to demonstrate that the $U$. S. military had a cutting edge air-breathing propulsion technology program. Given the world situation and the budgetary climate in 1983, the IHPTET program was well-received by the propulsion community. If there is an issue with this program today, it is that it has taken on a life of its own and has not been thoroughly re-thought since its inception.

The goals of the IHPTET program were to double the thrust to weight capability of aircraft engines by the end of the century, using 1983 as a reference. This goal is very ambitious, so ambitious that the temperature capabilities of metals were viewed as a major limitation. Thus, an enormous investment in "revolutionary materials" which held the promise of defeating the limitations of metals was well under way in 1988 and continues at present. Included in this class of materials were advanced composites with metal, ceramic and carbon matrices and intermetallic compounds. There also was more traditional work continuing to develop and field a higher temperature disk alloy, and work was in progress on the next generation cast superalloy for turbine blades.

Business was good in 1988, and company funded development money was relatively plentiful. In this climate and with a Soviet threat very much alive, the IHPTET program seemed like a logical next step. Further, on the strength of a growing defense budget, the IHPTET Program office continued to forecast substantial government funding for revolutionary materials development activities. This enhanced the palatability of the program. While there was very little evidence of an emerging industrial base for producing the revolutionary materials being developed to meet the IHPTET goals, discussion of this matter had been initiated. There was optimism that this matter would be resolved as soon as the new materials showed their potential. Today, the funding for IHPTET materials is still woefully inadequate. There has been modest progress in establishing an industrial base to produce these materials, but there still are no true production sources of rotor grade revolutionary materials, even today. In part, this is because the application of these materials in current (or even new) production systems has been so limited in extent that the word disappointing could be used. In the interim, diversion of significant sums of company funds into revolutionary materials development has occurred to keep the IHPTET demonstrator program on track. Today, the military markets are small enough that this practice cannot be sustained, particularly when the applicability of many of the IHPTET materials concepts to commercial products are increasingly doubtful.

Hindsight is a marvelous thing. Today, one wonders why engine companies ever expected that revolutionary materials would be rapidly adopted in production systems. Particularly since the time required to incorporate even incrementally improved metals is still 5 - 10 years after proof of concept. One explanation is that, in a technologically driven business, the tendency for technology push instead of product pull to dominate the planning process is well known and regularly demonstrated. As we move to a commercial business, this tendency must be addressed, and a new balance between these nominally opposing forces must be struck. Once the implementation of new materials technology begins to follow a product pull cycle, then other issues, such as an industrial base for the materials, will take care of themselves. The only troublesome point is that a complete transition to product pull technology planning can evolve into a process where there is no opportunity driven exploratory effort. Such an occurrence would have the 
unfortunate effect of slowing the generation of new materials concepts, some of which could, over time, comprise the basis for a comparative advantage of a new product.

The resolution of this paradox may be a more disciplined process for exploration of new materials concepts. The exploration of new materials concepts should be planned, managed, and conducted in distinct phases. Each phase should have well conceived "tollgates". Further, the concept should only be pursued in sufficient depth to establish its viability. At that point, no further effort should be expended until a market or product application is clearly identified and a pay-off analysis has been completed. The funding required to reach this level of maturity usually is relatively small. Thus, the amount of funding to support such efforts may be manageable, even in the current resource-limited business environment. Alternatively, joint projects to define the feasibility of high risk concepts could be undertaken cooperatively, even by historical competitors. This is now legal, provided the extent of the effort is limited to feasibility studies which fall into a class of activity now known as pre-competitive. Recent legislation has enhanced the ease with which these efforts can occur without fear of encountering anti-trust objections. In many cases today, barriers to precompetitive cooperation arise from the vestiges of traditional competition driven adversarial instincts. These barriers are more formidable than the legal ones. The propulsion materials community has recently shown the capacity and willingness to cooperate in the High Speed Civil Transport (HSCT) Program. This program, funded by NASA, represents a new way of doing business in this country. It provides some hope that we can change our ways in order to keep our industry competitive. Similar cooperation has been under way for about 6 years on the National Aerospace Plane (NASP).

Later in the section on IPD, it will be argued that a variety of means for rapid and efficient proof of concept demonstrations for new materials technology is necessary in an IPD environment. This is consistent with the need to ensure that the level of materials technology in successive generations of products progresses at a sufficient rate to be ready for timely introduction into new products.

Other development activities were under way in 1988 as briefly mentioned earlier. These continuing efforts are directed at incremental improvements in performance, cost, or reliability of metallic materials for growth engines and new centerline product engines. As much of this effort was process development related as it was directed toward defining new alloy compositions. Much of this effort was conducted with company funds, partly because of interest in holding the technology closely and partly because there has been limited federal funding for metallic materials and process development work since the inception of IHPTET. This is an expected result in any "fixed sum game", but the contraction in funding for metals still slowed some important initiatives.

The recent contraction in the military budget and the ongoing recession raise some pressing questions about the allocation of the remaining resources. For example, how much of this resource base can be devoted to developing materials which, in the foreseeable future, are only applicable to IHPTET ? As a minimum, it seems that the IHPTET portion should represent a constant fraction of the resource base, not a constant dollar amount. Further, the real IHPTET spin off benefits realized thus far should be analyzed with the reduced total resource base in mind. It is clear that IHPTET related materials technology has limited benefit to commercial engine technology. As the business centroid moves toward commercial applications, the relative value of IHPTET should be re-opened for discussion. If production engine 
applications of revolutionary materials cannot be found, the private sector investment in a production capability will not be forthcoming. Unless this "Catch-22" situation is resolved, the lack of production applications will become a self-fulfilling prophecy.

It may be time for some of the federal investment in revolutionary materials development to be re-directed to support improved metallic materials and advances in processing of these materials. This is generally being addressed in the emerging Presidential Initiative entitled Advanced Materials and Processing Program (AMPP), but the Defense Department has elected not to participate. This seems to an unfortunate turn of events, considering the reliance of military systems on better metals well into the next century. The funding situation for better metals is even worse than it may appear. The historic by-product of large weapons system development programs was program funds to develop improved materials for use in these systems. The current military budget trends show little prospect of being reversed in the foreseeable future. The net result is a major contraction in the funds available for developing metallic materials and processing methods. The majority of the R\&D funds remaining in the DoD budget and not tied to a specific program are programmed for IHPTET type materials. This leaves a serious shortfall in the area which can contribute directly to the ongoing success and competitiveness of both growth and new large commercial engines being developed for the world air travel industry. The front-loading of funding profiles required to make IPD a reality only worsen this matter, as will be described in the next section.

\section{The Effect of Integrated Product Development on Materials Technology}

The stated intent of IPD is to accomplish the various steps in product development in parallel instead of series. By using IPD, the product cycle is substantially shortened, the resulting product has more customer value, and the development costs are significantly lower. There are reasons to believe these claims. There also are reasons to argue that the benefits of IPD actually result from the exercise of greater discipline rather than IPD methodology per se. That is, the product development cycle time compression only allows the use of proven methods and technology. This in turn reduces wasted effort due to redesigns when a given technology does not prove to be mature enough to be suitable. It also means no costly "crash programs" when the rate of maturation of a method or a technology falls behind schedule. The value of reducing the engine development cycle time to less than that required for the relevant airframe is enormous. The weight of the airplane will be better known and the need to re-size the engine during development can be eliminated.

The question is: "what does an IPD environment mean to materials development?" The answer essentially is: "front loaded funding for materials development is required if mature new technology is to be included in a new product". If enforced, this requirement will change the way materials development has been funded in most companies. It also portends a slow down in the rate of incorporation of new materials technology, unless the traditional funding approaches are changed.

Historically, the time required to develop, prove, and field a new material has been longer than the engine development cycle time. If IPD permits the engine development cycle to be reduced (maybe by 50\%), the materials developers must learn to work differently. Failure to achieve commensurate reductions in materials development times means that new products will not benefit from the best materials concepts available. While funding is an issue, the typical empirical material or process development methodology is inherently slow. The materials community must make better use of new techniques and methods. Candidates include: 
computer based modelling and simulation, statistical design of experiments, and incorporation of processing from the outset. Modern characterization methods provide a wealth of sophisticated information, but an IPD approach coupled with working smarter also must be adopted. At some point, a long time high temperature exposure will always be required to verify alloy stability. We need better methods for selecting which alloy conditions to subject to these time-consuming tests to avoid multiple iterations of this type of test.

The message is quite clear as IPD becomes a way of life. Either change the way we work as materials developers or become second class contributors to new products. Considering the past materials related successes of aircraft engines, the choice is also clear. We must learn to work smarter and we must lobby our colleagues to provide the proper funding profile. Both are necessary ingredients, but we must do our part and not hide behind the question of funding. Until the recession abates, front loaded funding will pose a problem, but we can still start working differently and smarter immediately. This amounts to a sub-cultural transformation which we have within our grasp. The time to start is now. IPD is coming and we must be ready.

\section{Summary}

The preceding discussion has attempted to make several basic points which can be reduced to the following "bullets":

- Many changes in the business environment have occurred since the 1988 Seven Springs Conference on Superalloys.

- The aircraft engine business is rapidly changing from a military focus to a commercial one.

- Speed to market will assume greater importance in the engine industry.

- Greater attention to customer value will be required to remain competitive.

- There are policy issues which the Government can address to help the propulsion industry remain competitive.

- The amount of materials development resources allocated for IHPTET specific needs should be re-examined in light of the declining military budget situation.

- The propulsion industry must concentrate on reducing the product cycle to remain competitive.

- Integrated Product Development (IPD) will provide a framework and the discipline for reducing the product development cycle.

- The materials community must learn to work smarter to reduce their development cycle to keep pace with the impact of IPD.

- The materials community should not use funding as an excuse for not working smarter.

- The time to begin working differently and smarter is now.

\section{Acknowledgements}

I wish to acknowledge, with gratitude, the editorial suggestions and constructive comments of my colleagues, J. C. Chesnutt and G. Tarnacki. 